\title{
CORRESPONDENCE
}

The geography of disease

J R A Mitchell, fRCP . . . . . . . . . . 247

Epidemiology of multiple sclerosis

L Y C Lai, PHD, and Ann Thomas...... 247

Abortion (Amendment) Bill

D B Paintin, frCog................ 248

Psychoanalysis, psychotherapy, and

health services

H A C Mason, MRCPSYCH; B Barnett, MRCGP 248

Medical charities and prevention

N H Kemp, $M B$, and Brigadier K D

Gribbin, MA; Sir Ronald Bodley Scott,

FRCP, and J P Shillingford, FRCP........ 249

Comfort versus independence in

child development

K N Wilkinson, MRCP............ 250

Dietary fibre and blood pressure

A J Silman, MrCP. . . . . . . . . . . . . . . . 250

The need for gynaecological

oncology units

J H Shepherd, FRCs, and D Cavanagh,

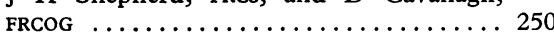

Preoccupation with hypertension

J A Moss, мв................. 251

An obstetrician epidural service

$G$ Roberts, MRCOG, and P J Bradley-

Watson, FRCSED ............... 251

Bicycles and health

H F Barnard, FRCPATH; W F S Sellers, MB. 251

The persistent salmon patch

J L Verbov, FRCP, and R Steinberg, MB . . . 2 251
First-aid treatment for acute coronary thrombosis A A Morgan, MD...

Effects of naloxone on pethidine-

induced neonatal depression

P C Wiener, FFARCS, and Sheila J Wallace,

FRCPED ....................... 252

Resuscitation of the newborn

M J Boscoe, fFarcs. . . . . . . . . . . . . 252

Towards fewer handicapped children

J H Smith, мв.............. 252

Monitoring blood glucose

A H Knight, MRCP; T E T West, MD, and

others; C M Kesson, MRCP, and others... . 253

Postoperative analgesia

A G Leitch, MRCP; H A F Dudley, FRCs... 253

Bromocriptine as sole treatment

for acromegaly

$\mathrm{R} N$ Corston, $M R C P$, and $\mathrm{R}$ B Godwin-

Austen, FRCP................ 254

Opiates in acute abdominal pain and

head injury

E Moss, fFARcs, and D G McDowall, FFARCS

Haemodialysis and transplantation in

Wegener's granulomatosis

J R Salaman, FRCS.

Pathogenesis of acute renal failure

E N Wardle, MD................ 25

Treatment of liposclerosis

H L Muston, MRCP..........
Misericordiae medicinae

M Livia Osborn.
Prognosis after myocardial infarction

W Casscells, MD............... 255

Tardive dyskinesia

P C Elmes, FRCP.................. 255

Iron treatment in the elderly

B N C Littlepage, MrCog, and R E A

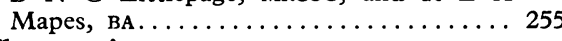

The practice nurse

E V Kuenssberg, PRCGP. . . . . . . . . . . 255

In defence of clinical freedom

M R Baker, MRCP................ 255

Domiciliary visits by consultants

P E Jackson, FRCP. . . . . . . . . . . . 256

Short-term certification

A K Walker, MrCGP.............. 256

Medical confidentiality and DHSS

M A Birnstingl, FRCS.............. 256

Misleading names?

B S Smith, FRCP............. 256

A decade for the patient

D L Gullick, мB................. 256

"Man Alive" on ethics

T Slessor...................... 257

Points The undiscovered country (L H Worth); Scrum-pox caused by herpes simplex virus (F Williams); Unnecessary smallpox vaccination (J Twomey); Medical charities and prevention (D F Reynolds); Drug names that look or sound alike (D C W Hilton); Treatment of watering eye (J H Kelsey); Women and general practice (Julie S Shepherd); No Christmas Holiday (M G McVerry)....................257

We may return unduly long letters to the author for shortening so that we can offer readers as wide a selection as possible. We receive so many letters each week that we have to omit some of them. Letters must be signed personally by all their authors. We cannot acknowledge their receipt unless a stamped addressed envelope or an international reply coupon is enclosed.

Correspondents should present their references in the Vancouver style (see examples in these columns). In particular, the names and initials of all authors must be given unless there are more than six, when only the first three should be given, followed by et al; and the first and last page numbers of articles and chapters should be included. Titles of papers are not, however, included in the correspondence section.

\section{The geography of disease}

SIR,-The intriguing paper by Dr D J P Barker and his colleagues (1 December $\mathrm{p}$ 1389) on the differential prevalence of gall stones in nine towns in England and Wales provides further evidence of the considerable geographical, social, ethnic, and cultural differences which exist within the British Isles. The authors draw attention to a negative correlation between prevalence of gall stones and standardised mortality ratios for ischaemic heart disease in their nine towns. It is of interest that this negative correlation can be further subdivided, for if one compares their findings in respect of gall stones for men and women with the death rates per 100000 for atherosclerotic and coronary disease (ICD 420) in men and women aged 45-64 a differential pattern emerges between the sexes. In men the correlation coefficient is -0.45 and is not significant whereas for women it is -0.63 and is significant at the $p<0.05$ level.

Studies such as those by Dr Barker and his colleagues serve to remind us of the multifactorial nature of the majority of chronic conditions, and of the folly of seeking to implicate single factors in isolation as "the cause" of diseases such as coronary disease and gall stones. Evidence is accumulating that one cannot even draw general conclusions from closely defined groups within a given local community. We have recently completed a study of cardiovascular risk factors in Nottingham teenagers (in press and unpublished observations) and have found striking differences between the patients registered with our three participating general practices. These differences include not only labile variables such as urate and lipid concentrations and

\section{Epidemiology of multiple sclerosis}

SIR,-We have read with interest your leading article comments (1 December, $p$ 1386) on th subject of epidemiology of multiple sclerosis.

We agree that multiple sclerosis can be attributed to the interaction of both environment and heredity, with environment thought to exert a greater influence on the manifestation of the disease. While it cannot be denied that epidemiological studies have provided most of the information on environmental factors, most studies are based on residences to ascertain the geographical distribution of arterial pressure but inbuilt markers such as the distribution of the ABO blood groups.

Dr Barker and his colleagues are to be congratulated for reminding us that even within a small country such as ours the study of geographical differences in disease prevalence is a fascinating and worthwhile exercise.

Department of Medicine,

J R A Mitchell multiple sclerosis. We wish to point out that the use of residence as a variable in the research not only is inadequate because the resultant estimate of incidence or prevalence, or both is misleading, but it underscores the underlying importance of past environmental influences during prenatal and perinatal periods of individuals who express multiple sclerosis later in life. We have data to indicate the importance of such influences which will be published in due course. In the meantime the purpose of this letter is to demonstrate the 
importance of the employment of both birthplaces and residences in the study of distribution of multiple sclerosis, using survey data from the State of New South Wales, Australia. We hope that the following short observations may help to clarify this.

In 1974 a postal survey was conducted of the distribution of the disease in Australia through various state societies of multiple sclerosis. Responses of patients were followed up and the diagnosis was confirmed by their attending general practitioners and neurologists. In this way a total of 233 patients were sampled and 17 of these were excluded because they were diagnosed as having only possible multiple sclerosis or a disorder other than the one under investigation. The remaining 216 patients were confirmed as definite cases of multiple sclerosis. The table shows the analysis of patients by birthplace and by residence, the residence being classified as private dwelling or hospital in the metropolitan Sydney area and in areas outside metropolitan Sydney.

Distribution of multiple sclerosis patients by both birthplaces and residences of New South Wales

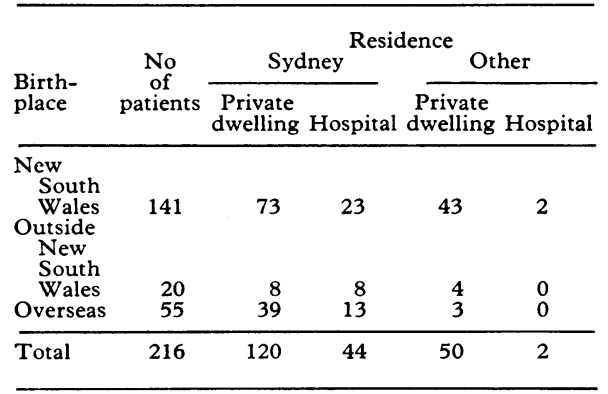

There are significant differences $\left(\chi^{2}=\right.$ $14.48, \mathrm{p}<0.001)$ in the distribution of patients between those living in Sydney and those outside Sydney with reference to three categories of birthplaces-namely, New South Wales, outside New South Wales, and overseas. In addition, the analysis of patients by residence does not correspond with that by birthplaces, the difference being significant $\left(\chi^{2}=\right.$ $6 \cdot 77, \mathrm{p}<0.01$ )

The conclusion to be drawn from the data is that any epidemiological study of multiple sclerosis should include birthplaces as an adjunct to residences and population censuses.

LAWRENCE Y C LAI ANN THOMAS

School of Community Medicine,

University of New South Wales,

Sydney, NSW 2033,

Australia

\section{Abortion (Amendment) Bill}

SIR,-Mr J Corrie's Abortion (Amendment) Bill will reach the report stage in the House of Commons on 8 February. Clause 1 would allow abortion up to 20 weeks if there was a risk to life or of serious injury to physical or mental health. The risk of continuing the pregnancy would have to be substantially greater than the risk from abortion. The words serious and substantial do not appear in the 1967 Abortion Act. The decision to request abortion is often difficult and usually distressing for the woman. Counselling, the skill of helping her to come to the best decision, can be honest only if the doctor feels free to recommend and perform the abortion, or to help her to continue the pregnancy once she has examined all aspects of her situation. The word serious is difficult to define and would make doctors feel less free to offer neutral counselling. Consequently some women would not obtain the legal abortions they considered essential.

Clause 4 of the bill would result in extreme difficulty for the woman who wished to obtain a private abortion. She would have to find three independent doctors. The first two would counsel her and would sign the statutory green form if they felt that her abortion would be within the law. The third would have to be willing to perform the abortion on the basis of the two signatures on the form. It would be illegal for the operating doctor to advise the woman about her abortion decision or for him to have advised any other pregnant woman about abortion in the previous six months.

$\mathrm{Mr}$ Corrie and his sponsors appear to believe that doctors who see private patients do not offer neutral counselling but, instead, persuade women to have abortions they do not really want, so obtaining a larger fee. In fact, most women consult a doctor about abortion only after they have reluctantly taken the decision that the pregnancy is unwanted. Only a minority are uncertain about their need for abortion by the time they consult. In my experience in the Health Service $93 \%$ of women who are referred for consideration of termination have an abortion. Five per cent change their minds after counselling and $2 \%$ are not actually pregnant. Those who have talked to women requesting abortion know the strong motivation felt by these women, motivation so strong that they will risk illegal abortion if refused.

Clause 4 is designed to prevent legal abortion by the gynaecologist with a private practice and by the charitable organisations, the British Pregnancy Advisory Service and the Pregnancy Advisory Service. The latter perform $30 \%$ of all the abortions performed on British women. They provide neutral counselling and perform terminations on $95 \%$ of the pregnant women they see, a proportion similar to my own and that of many other units in the Health Service. The proper management of a woman who has an unplanned pregnancy calls for a team to give continuity of care-counselling, safe abortion, contraceptive advice, and post-abortion support. This occurs at present but would not be possible if the three doctors necessitated by Mr Corrie's bill were not allowed to work together.

The Health Service lacks the resources to meet the abortion needs of the community and for the last few years has performed only about $50 \%$ of legal abortions on British women. The charitable organisations perform $30 \%$ of British abortions. The Health Service would be unable to cope with the large number of extra abortion requests that must occur if Mr Corrie's bill becomes law. There would be many more illegal abortions and an increase in the birth of children to women who lack the physical and emotional resources to be adequate parents. The 1967 Abortion Act has provided satisfactory legal abortion and has not been shown to have been abused. It does not need amending in the manner proposed by Mr Corrie.

D B Paintin

Department of Obstetrics and Gynaecology, St Mary's Hospital Medical School,
Psychoanalysis, psychotherapy, and health services

SIR,-After reading Professor $M$ Shepherd's (15 December, $p$ 1557) sometimes entertaining article, one is left wondering whether he has really grasped the nettle or only a minor one, and at the same time given vent to various traditional fears which used to concern psychiatry in general, and partly still do. Is he also not too precise about a diffuse subject still developing in directions which appear conflicting, but may be different aspects of the same thing? Quoting Freudian excesses in America-that land of extremes-and the cautious opinion of a lawyer, however eminent, does not necessarily clarify the situation in England.

Equally, I am aware that there is not much space here to support my views. I am, however, describing how psychotherapy actually works and is accepted in a teaching hospital. I would admit that my results are somewhat better with private patients, and there may be other factors here, but this is not a reason for denying psychotherapy under the Health Service. The lack of time has been consistently pointed out, finally with some effect. The witch doctor could indeed be the forerunner of the physician as well as the psychiatrist and the psychotherapist, and most patients in their feeling of illness can be immaturely dependent on their doctor. Are psychotherapists' patients really so much different from psychiatrists' and for that matter physicians' patients? There are indeed difficulties, but I find Professor Shepherd's attitude alarmist. Has he forgotten the long line of physical treatments scientifically validated in various degrees-insulin coma and modified insulin, acetylcholine, carbon dioxide inhalation, cardiazol and methedrine injections? Even now electric convulsive therapy and the major tranquillisers and antidepressants come under dispute. This is the march of science and it is the doctors' duty to learn and discriminate.

I am certain there are many psychotherapists who have worked in the NHS since it started, as I did. Further, I never made any bones about my basic approach being analytic, but I also learned the use of drugs and abreaction, and later looked hard at behaviourist approaches, noting that in some ways one could restate the process of analysis in terms of conditioning. No originality is claimed. All this time one continued to work in a teaching hospital noted for its physical approach. My colleagues never failed to refer more cases than I could comfortably treat in four sessions, and there has always been referral in both directions, with discussion, mutual respect, and help. Surely, with their strongly held views, they would not have gone on referring cases if the psychotherapeutic approach was valueless? I agree that with so many variables it is extremely difficult to arrange controlled trials.

Other special lines of development must be allowed to continue; but I believe that more and more psychotherapists, at least in hospital practice, are admitting that their equipment should not be too one sided, though they may feel more at ease with certain lines of approach. Certainly in a teaching hospital I think it is extremely important that students should be shown the emotional as well as the chemical links between symptoms and how the picture can be influenced in either direction. Contrary to what a casual reader might glean from the article, explicit provisions exist in the Health Service for the appointment of psychotherapists, and before I retired from my hospital the Royal College of Psychiatrists had estimated that the job needed two consultant psychotherapists with nearly three times the sessions between them.

The position of psychologists undertaking psychotherapy presents a further complication as they are highly trained people and there may be a tendency to repeat the struggle for ascendency which occurred in the Army; and of course they play a considerable part in selection in industry. 